\title{
COMPORTAMENTO DA MULHER MASTECTOMIZADA FRENTE ÀS ATIVIDADES GRUPAIS
}

\author{
Ana Fátima Carvalho Fernandes* \\ Maria Socorro Pereira Rodrigues* \\ Pacífica Pinheiro Cavalcanti**
}

\section{Resumo}

Objetivamos descrever as reações da mulher frente à mastectomia e sentimentos emergidos da interação grupal. Foram entrevistadas 10 mulheres integrantes do grupo GEPAM (Grupo de Ensino, Pesquisa, Auto-ajuda e Assistência à Mulher Mastectomizada) nos meses de novembro e dezembro de 2001 a janeiro de 2002. Das reações frente a mastectomia, destacamos: depressão, discriminação, adoção de novos comportamentos e necessidade de interação social. A amizade e a curiosidade foram sentimentos revelados na interação grupal. Estes aspectos levam a compreender que as atividades grupais exercem forte importância na minimização dos conflitos decorrentes da mastectomia, assim como, na valorização dos sentimentos dessas mulheres, de forma a proporcionar uma reabilitação mais eficaz e melhor qualidade de vida.

Descritores: comportamento; câncer de mama; mulheres mastectomizadas; atividades grupais

\begin{abstract}
We aim to describe the reactions of women confronting mastectomy, and the feelings that emerged from group interaction. 10 women from the GEPAM group (Teaching, Research, Self-help and Assistance to Mastectomized Women Group) were interviewed in November and December 2001 and January 2002. Reactions in the face of mastectomy can be singled out as: depression, discrimination, adoption of new behavior and the need for social interaction. Group interaction revealed feelings of friendship and curiosity. These aspects lead us to understand that group activities are important in minimizing the conflicts associated with mastectomy and also in valuing of the feelings of these women, to provide more effective rehabilitation and better quality of life.
\end{abstract}

Descriptors: behavior; breast cancer; group activities; mastectomized women

Title: The performance of mastectomized women in group activities

\section{Resumen}

Es nuestro objetivo describir las reacciones de la mujer frente a la mastectomía y los sentimientos resultantes de la interacción grupal. Se entrevistaron a 10 mujeres integrantes del grupo GEPAM los meses de noviembre y diciembre de 2001 hasta enero de 2002. De las reacciones se puede señalar: la depresión, la discriminación, la adopción de nuevas conductas y necesidad de interacción social. La amistad y la curiosidad son sentimientos que se revelan en la interacción grupal. Dichos aspectos nos hacen comprender que las actividades de grupo ejercen fuerte importancia para minimizar los conflictos que decurren de la mastectomía, así como, para valorizar los sentimientos de esas mujeres, de tal forma que les proporcione una rehabilitación más eficaz y con mejor calidad de vida.

Descriptores: comportamiento; cáncer de mama; mujeres mastectomizadas; actividades grupales.

Título: Comportamiento de la mujer mastectomizada frente a las actividades de grupo

\section{Introdução}

A retirada da mama é um processo cirúrgico, considerado agressivo, visto ser acompanhado de conseqüências, muitas vezes, traumatizantes, nas experiências de vida, e por afetar a saúde da mulher acometida de câncer.

A doença expõe as mulheres a uma série de dificuldades, tais como o desajuste psicológico devido essa doença crônica e mutilante. Ocasiona e limita os movimentos, no caso do membro superior correspondente à mama afetada, impossibilitando a mulher de desenvolver trabalhos domésticos e atividades profissionais exercidas anteriormente.

O câncer é uma das doenças que mais induz sentimentos negativos em qualquer um de seus estágios: o choque emocional causado pelo impacto ao tomar conhecimento do diagnóstico; o medo da cirurgia; a incerteza do prognóstico e de uma recorrência deste câncer; os efeitos do tratamento da radioterapia e da quimioterapia; o medo da dor e o pavor de encarar a morte nas circunstâncias com essa que em geral se apresenta $^{(1)}$

Com a finalidade de auxiliar essas mulheres mastectomizadas na resolução dos problemas decorrentes do câncer e da mastectomia, têm sido criados, atualmente, muitos grupos de auto-ajuda, os quais são grupos terapêuticos e homogêneos, que visam congregar pessoas que passam pela experiência de ser acometida por um câncer. Esses trabalhos em grupo são conhecidos como self-help, fundamentam-se em ajudar as pessoas a resolver ou minimizar problemas relacionados a traumas decorrentes do acometimento de doenças de natureza aguda, e, em especial, crônicas ${ }^{(2)}$.
O valor dos grupos de auto-ajuda é destacado quando "o compartilhar experiências comuns, proporciona aos seus integrantes uma enorme energia, que pode ser carreada para as exigências da vida, para a ressocialização e para a recuperação"(3:77).

Os grupos de auto-ajuda são considerados componentes importantes no processo de reabilitação da mulher mastectomizada, assim como, na sua aceitação do câncer e da condição de mulher que foi submetida a uma mastectomia. Proporcionam o compartilhar de experiências de vida, relacionadas à enfermidade e à busca coletiva de meios de soluções para os problemas.

Portanto, diante da importância e necessidade de assistência à mulher mastectomizada, propusemos-nos a estudar a problemática dessa mulher através dos seguintes objetivos: descrever as reações da mulher frente à mastectomia e os sentimentos emergidos a partir da interação grupal.

\section{Metodologia}

Esta pesquisa é de caráter descritivo e exploratório, que tem como enfoque essencial conhecer traços, características e problemas de um indivíduo, grupo ou comunidade, e visa aumentar a experiência do pesquisador em torno do assunto(4). A presente proposta se reporta à importância de grupos de auto-ajuda na reabilitação da mastectomizada, tendo em vista a problemática decorrente desse evento, o qual repercute nos mais diversos aspectos da vida de uma pessoa, desde os psicológicos, passando pelo sociofamiliar e, em particular, pelo espiritual.

\footnotetext{
* Enfermeira. Professora Doutora do Departamento de Enfermagem da Universidade Federal do Ceará. **Acadêmica de Enfermagem da Universidade Federal do Ceará - Bolsista PIBIC/CNPq

E-mail do autor: afcana@ufc.br
} 
Este estudo foi desenvolvido com mulheres que freqüentam um Grupo de Ensino, Pesquisa e Assistência à Mulher Mastectomizada (GEPAM), o qual funciona na área física do Departamento de Enfermagem da Universidade Federal do Ceará.

Participam do GEPAM mulheres mastectomizadas do tipo unilateral e bilateral, algumas passando pela experiência de reconstrução mamária, cuja faixa etária varia de 36 a 70 anos. O estado civil das mulheres varia em casadas, solteiras, viúvas e amasiadas. Suas ocupações variam entre dedicação ao lar, confecção e venda de bijuterias e aposentadas sem uma ocupação mais definida.

Foram incluídas na pesquisa mulheres de qualquer idade, crença, procedência, nível socioeconômico ou educacional, tendo sido estabelecidos os seguintes critérios:

Mulheres que apresentassem disponibilidade e aceitação para participar voluntariamente do estudo, concedendo autorização prévia verbal e por escrito para a efetivação da entrevista;

Mulheres que estivessem participando do grupo há pelo menos três meses, e que mantivessem uma freqüência regular no grupo.

As dez mulheres, incluídas no estudo, receberam nomes fictícios de personagens femininas da mitologia grega, visando preservar o anonimato.

Após as exigências regimentares de trâmites no Comitê de Ética, e a autorização concedida pelas participantes, passouse à coleta de dados, a qual foi realizada semanalmente, nos meses de novembro de 2001 a janeiro de 2002 .

Utilizamos um roteiro de entrevista semi-estruturado, contendo questões abertas, oferecendo ao entrevistador uma certa liberdade para fazer adaptações conforme ocorresse necessidade, sem ter que seguir rigidamente uma ordem préestabelecida. Oferece também ao entrevistado a possibilidade de discorrer sobre o tema proposto, sem respostas prefixadas pelo entrevistador ${ }^{(5)}$.

As respostas aos questionamentos foram anotadas pelo pesquisador, conforme a permissão, concedida pelas mulheres, tendo em vista a importância de se obter uma descrição detalhada das informações fornecidas pelas mulheres.

Após a leitura dos depoimentos das mulheres, estes foram organizados em categorias de acordo com a similaridade de idéias contidas nos mesmos, conforme método de análise de conteúdo, que define categorização como uma operação que classifica elementos constitutivos de um conjunto, por diferenciação e por reagrupamento, considerando suas características particulares e conforme critérios previamente definidos $^{(6)}$

As categorias foram criadas, a partir do significado emergido dos discursos e categorizadas nas seguintes temáticas: Reações frente a Mastectomia e Sentimentos emergidos da Interação Grupal. Foram posteriormente analisados, tendo-se em vista conceitos e circunstâncias, conforme o referencial teórico da psicologia social.

\section{Análise e discussão dos resultados}

Conforme o plano de organização e análise dos dados, esses vêm assim categorizados:

\subsection{Reações frente à mastectomia}

Essa categoria foi subdividida em subcategorias pertinentes às reações que a mulher apresenta em decorrência à retirada de sua mama.

\subsubsection{Depressão}

A depressão está intimamente relacionada ao câncer, pois estudos demonstram que mesmo antes do diagnóstico, a pessoa portadora de câncer já se encontra deprimida, pois na maioria dos casos existe uma grande tendência para reprimir emoções como a raiva, a tristeza e o medo, podendo gerar um estado de depressão crônica.

Para Simonton(7) "a própria natureza do câncer, com seus altos e baixos, sua incerteza quanto ao futuro, a possibilidade de uma recidiva e da morte cria períodos de depressão"(7:49). Sabendo-se ainda que a depressão acarreta estados de distonias, assim como, estados de amnésias passageiras e de outras intercorrências. Constituindo, por esse motivo, um momento em que a paciente necessita de redobrada atenção, a fim de prevenir-se atitudes de auto ou hetero-destruição. As mulheres participantes do estudo expressaram claramente esse momento de depressão, nos seguintes termos: [...] Porque eu estava muito sensível, qualquer coisa eu estava chorando, me aborrecendo facilmente. Pensei até em me suicidar (Medusa).

Sabe-se que a mastectomia, cirurgia em que se retira a mama, é em geral indicada em decorrência de uma neoplasia maligna. O fato de constituir um processo cirúrgico agressivo pode desencadear desajuste psicológico na mulher, tendo em vista o caráter mutilador dessa cirurgia. Nos primeiros anos que se seguem a mastectomia, a depressão é, via de regra, uma reação comum, podendo atingir até a metade das mulheres que se submetem a essa cirurgia $^{(1)}$.

\subsubsection{Discriminação}

Apesar de todo avanço na área científica, as pessoas portadoras de alguma neoplasia maligna, ainda, se ressentem de algum tipo de discriminação, como por exemplo, o isolamento social, o que pode ser evidenciado no seguinte discurso:

[...] É muito ruim a gente ter um caso desse e viver isolada. Às vezes a gente está cheia de problemas em casa [...] (Medusa).

O próprio nome câncer é tido como possuidor de um danoso poder mágico, como se a simples pronúncia dessa palavra acarretasse o agravamento ou até mesmo a transmissão daquela doença( ${ }^{(8)}$.

Nas reuniões do GEPAM as mulheres interagem mutuamente, compartilhando experiências de forma que possibilitam a compreensão e a solução de seus problemas e facilitam enfrentar a condição de ser mastectomizada.

\subsubsection{Adoção de novos comportamentos}

O câncer é uma patologia em que não se pode, ainda, determinar com precisão a causa, mas vários estudos comprovam a estreita ligação existente entre o câncer e a repressão de sentimentos.

É difícil para muitos acreditar que o câncer possa oferecer algum tipo de ganho secundário, mas a experiência de se defrontar com uma doença grave, possibilita ao paciente se beneficiar de mudanças positivas em sua vida, tais como: ir ao encontro de alguns desejos não realizados, priorizar a busca de uma melhor qualidade de vida, exprimir sentimentos que antes eram reprimidos, satisfazer necessidades que antes eram renegadas, desenvolver a capacidade de dizer não e perceber mais claramente que é um ser mortal(7). seguem:

Essas mudanças são enfatizadas nos depoimentos que

[...] Eu não me frustro, eu falo, eu me abro (Pandora). [...] Eu era muito fechada, eu mudei muito (Artêmis).

Vê-se pelas falas a disposição renovada de Pandora e Artêmis em exteriorizar seus sentimentos, estando conscientes dos benefícios que podem surgir em decorrência desse ato. As reuniões grupais facilitam a exteriorização de sentimentos e aumentam a relação de ajuda com os membros do grupo.

\subsubsection{Necessidade de interação social}

As mulheres mastectomizadas entrevistadas revelam que a interação e a partilha de experiências com pessoas que sofrem dos mesmos problemas é uma forma de se incluir no 
grupo, de serem apoiadas e a partir daí conseguirem externar seus sentimentos. Neste sentido, foram destacados os seguintes discursos:

Muito importante [...] a gente partilha [...] tem necessidade de ouvir a outra.É uma forma de apoio (Atena).

Troca de experiências, sinto-me muito bem (no grupo) É onde eu me identifico (Pandora).

As palestras, o relaxamento e a troca de experiências (Helena).

É muito bom (o grupo), fico torcendo que chegue sextafeira. Esse ambiente de conversar, de dialogar, é muito bom (Pandora).

[...] Aqui (no grupo) a pessoa se distrai, não fica pensando besteira (Hera).

A convivência entre as mulheres que vivenciaram situação com o câncer de mama parece ser um ponto chave na reabilitação das mastectomizadas. Além de diminuir o estigma e 0 isolamento social associados à doença(3).

Nas reuniões, as mulheres manifestam necessidade de interação social, de se relacionarem com outras pessoas que passaram pelo mesmo problema e de buscarem esclarecimentos para as eventuais dúvidas que surgem em decorrência do câncer e o que fazer para continuar vivendo de forma mais saudável e mais feliz.

As entrevistadas referiram que a integração grupal funciona, também, como um espaço de equilibro. Muitas enfatizam, que o tempo em que estão no grupo é um dos poucos momentos de suas vidas em que se sentem bem e se divertem. Vale ressaltar que a grande maioria não dispõe de condições socioeconômicas que favoreçam qualquer tipo de lazer.

Pode-se perceber, inclusive, que essas mulheres utilizam termos bastante eloqüentes, do tipo: coisa maravilhosa, é muito importante, para traduzir seu contentamento relacionado ao fato de pertencerem ao grupo. São, portanto, esses aspectos que nos levam a compreender que elas consideram o grupo como um espaço de real significado para suas vidas.

O grupo GEPAM utiliza um espaço amplo, com condições adequadas para a realização das atividades. São realizados exercícios corporais, com intuito de promover relaxamento físico e mental, e promover a reabilitação do membro superior afetado pela mastectomia. Além dos exercícios físicos, a equipe multiprofissional integrante do GEPAM oferece atividades que favorecem uma melhoria da saúde mental, com a finalidade de diminuir o máximo possível, de forma significante, as crises de depressão e de angústia.

\subsection{Sentimentos emergidos da interação grupal}

Nesta categoria destacamos, em particular, os sentimentos das mulheres eclodidos no grupo, elementos de fundamental importância em seu processo de adaptação social.

\subsubsection{Amizade}

O compartilhamento de sentimentos e reações, a partir de um relacionamento que favoreça a discussão e exploração das idéias dos participantes constitui formas poderosas de terapia para o câncer de mama. Conseqüentemente o fortalecimento do relacionamento com outras pessoas implica em uma resposta favorável do sistema imunológico, tanto mais forte e eficaz quanto possa ser reforçado pelos demais sistemas do organismo ${ }^{(1)}$.

É muito bom conversar com as outras, a amizade com as meninas (Helena).

É uma hora de lazer, de amizade (Afrodite).

É muito importante, venho para cá, sinto-me bem, a amizade (Medusa).

Rotineiramente, nas reuniões do GEPAM, são reservados momentos em que as mulheres interagem, particularmente, entre elas mesmas. É nessas ocasiões que elas percebem, que não são as únicas a ter câncer. A partir dessa percepção, elas descobrem que podem se ajudar mutuamente, uma vez que uma mais experiente pode esclarecer dúvidas da outra, aconselhar e até mesmo apoiar, dependendo da ocasião. A partir desses momentos, surge então a descoberta de sentimentos, tais como é o caso da amizade.

\subsubsection{Curiosidade}

As mulheres, quando submetidas à retirada da mama, sentem necessidade de se manterem informadas sobre tudo que diz respeito à sua saúde. As mulheres que tratam com sucesso o câncer de mama buscam informações, de modo particular sobre seu problema, comportamento esse que parece estar relacionado com a resistência à doença física ${ }^{(1)}$.

As informações. Sou muito curiosa, quanto mais eu sei, mais quero saber sobre essa doença (Afrodite). (Hera)

[...] Sinto-me muito bem informada e feliz (no grupo).

Uma coisa maravilhosa [...] As informações sobre saúde que aqui recebo (Céris).

Os profissionais do GEPAM mostram-se disponíveis e capacitados para ajudar as mulheres a se sentirem capazes e responsáveis para contribuir com sucesso no tratamento e conseqüentemente, viver de forma mais saudável.

Temos percebido através das situações práticas desenvolvidas com as mulheres que participam do GEPAM, que essas valorizam muito os momentos que são dedicados aos esclarecimentos das suas dúvidas. Os profissionais, sempre que possível, realizam cursos, seminários e palestras que objetivam deixar essas mulheres bem informadas e instruídas a respeito de sua condição no que tange a serem mastectomizadas.

A psicoterapia tem por objetivo ensinar essas mulheres a se cuidarem da maneira que elas acreditem que irão se curar, facilitando assim as intervenções médicas tradicionais ${ }^{(1)}$.

\section{Considerações Finais}

As mulheres que tiveram a experiência de serem acometidas por um câncer de mama apresentam muitas reações atribuídas ao fato de terem sido mastectomizadas, tais como: a depressão e a discriminação devido ao caráter estigmatizante que o câncer, ainda, possui. Para minimizar os efeitos negativos que essas reações representam, essas mulheres procuram um grupo de auto-ajuda, que trabalha tendo em vista criar situações para ajudar seus participantes a exteriorizar mutuamente suas dificuldades, o que as ajudará a transpor com melhor desempenho os vários obstáculos surgidos em decorrência da mastectomia.As mulheres são forçadas a adotarem mudanças de comportamento, em decorrência do câncer, o que tem um aspecto positivo, que é favorecer a essas mulheres uma melhor qualidade de vida. Elas admitem que, a partir da doença, passaram a ter vidas melhores e mais plenas.Pode-se afirmar que a interação grupal favorece um espaço em que se percebe claramente o bemestar das integrantes, expandindo horizontes e estabelecendo laços de amizade fortalecida com a vivência grupal.

A enfermagem exerce fundamental importância nos trabalhos realizados nesses grupos, em especial no sentido de minimizar os conflitos identificados, através do ensino do autocuidado e da valorização do indivíduo como um ser único, com seus medos e suas dúvidas, visando promover um crescimento individual, a partir da aceitação espontânea de cada indivíduo em sua singularidade, dando-lhe estímulo e apoio. Cabe também à enfermagem buscar a elucidação de dúvidas que surgem em decorrência do tratamento oncológico, podendo deixar a paciente menos apreensiva e mais crente no seu processo de cura.

Reforçamos a importância da atuação do enfermeiro no preparo do paciente com câncer, para enfrentar dificuldades emocionais, visto que o cuidado deve abranger o apoio emocional, através de um profissional presente e atencioso, 
requisito característico da arte de cuidar em enfermagem, e que caracteriza assistência como humanizada. O papel expressivo da enfermeira consiste em cuidar das pessoas de forma integral, total, reconhecendo os principais fatores psicológicos, sociais, espirituais e ambientais, que afetam o bemestar da paciente, ajudando-a viver de forma mais saudável.

A assistência à mulher mastectomizada não deve focalizar apenas a doença e a reabilitação física; deve abranger um contexto amplo, que envolva os aspectos culturais, educacionais, econômicos e sociais de cada uma das mulheres envolvidas no trabalho do grupo ${ }^{(6)}$.

É importante que o enfermeiro saiba identificar todas as necessidades que uma paciente mastectomizada apresenta, para então estabelecer cuidados mais efetivos no programa de assistência, respeitando a integralidade e a individualidade do ser humano em questão, facilitando, dessa forma, uma completa reabilitação, tanto física quanto psicológica promovendo uma melhor qualidade de vida e de saúde.

\section{Referências}

1. Deitos TFH, Gaspary JFP. Efeitos biopsicossociais e psiconeurológicos do câncer sobre pacientes e familiares. Revista Brasileira de Cancerologia; Rio de Janeiro 1997;43(2):117-26.

2. Zimerman DE, Osório LC. Como trabalhamos com grupos. Porto Alegre (RS): Artes Médicas; 1997.

3. Zukerfield R. Act bulímico, cuerpo y tercera tópica. Buenos Aires: Ricardo Vergara; 1992.

4. Triviños ANS. Introdução à pesquisa em ciências sociais. São Paulo: Atlas;1993.175p.

5. Ludke M, André MED. A Pesquisa em educação: abordagens qualitativas. São Paulo: EPU;1986.

6. Rodrigues MSP, Leopardi MT. O Método de análise de conteúdo: uma versão para enfermeiros. Fortaleza (CE): Fundação Cearense de Pesquisa e Cultura;1999.118 $p$.

7. Simonton SM. A família e a cura. São Paulo: Summus; 1990.

8. Sontag S. A Doença como metáfora. Rio de Janeiro: Edições Graal; $1984.108 \mathrm{p}$.

Data de Recebimento: 20/05/2003

Data de Aprovação: 30/04/2004 